\title{
Evaluation the Scramjet Cooling Heat for Available Work Using Exergy Analysis
}

\author{
Xinchun Li ${ }^{1}$, , Heyang Miao ${ }^{2}$, Zhongwei Wang ${ }^{2}$, Yaobin Niu ${ }^{2}$ \\ ${ }^{1}$ Theoretical Training Department, the Air Force Xi' an Flight Academy, Xi'an, China \\ ${ }^{2}$ Science and Technology on Scramjet Laboratory, National University of Defense Technology, Changsha, China
}

Email address:

xch_lee@163.com (Xinchun Li)

To cite this article:

Xinchun Li, Heyang Miao, Zhongwei Wang, Yaobin Niu. Evaluation the Scramjet Cooling Heat for Available Work Using Exergy Analysis. International Journal of Energy and Power Engineering. Vol. 7, No. 4, 2018, pp. 47-53. doi: 10.11648/j.ijepe.20180704.11

Received: July 13, 2018; Accepted: October 11, 2018; Published: November 12, 2018

\begin{abstract}
The scramjet cooling heat has a big potential work between the heat and the fuel coolant. However, there is no idea about the maximum potential work of the heat from cooling scramjet. Therefore, the potential work of the scramjet cooling heat is studied. The maximum available work from the heat of cooling scramjet is evaluated by the exergy analysis. The heat exergy analysis model is proposed under the heat sources condition according to the heat transfer performance of the scramjet wall and fuel coolant. It is supposed that a closed thermodynamic system is performed between hot source and cold source. The heat flow, the heat exergy and the available work from the scramjet wall are $543.1 \mathrm{~kW}, 407.3 \mathrm{~kW}$ and $370.3 \mathrm{~kW}$, respectively, when the temperature of scramjet wall is $1200 \mathrm{~K}$. And the exergy efficiency of the closed system is $68.2 \%$. The exergy losses of external irreversible processes between the closed system and heat sources are analyzed by considering the heat exchanging temperature differences. The external exergy losses and the exergy efficiency have been largely changed with the heat exchanging temperature differences between the closed system and heat sources. The heat exchanging temperature differences are decreased, the external exergy losses are decreased and the exergy efficiency is increased. However, the heat exchanging temperature differences would be adapted to heat exchanging processes and decreasing the acreage of heat exchange. It is meaningful for having a guidance of power generation for hypersonic vehicle.
\end{abstract}

Keywords: Scramjet, Exergy, Available Work, Exergy Loss

\section{Introduction}

The key technology of hypersonic vehicle has been studied for many years, especially the issue for hypersonic airbreathing vehicle [1-3]. The key technology of the scramjet is more important for hypersonic vehicle and the cooling of scramjet is one of key issues. Because the scramjet has great amount of heat fluxes which is about $7 \sim 8 \mathrm{MW} / \mathrm{m}^{2}$ in NASA-Langley airframe propulsion integrated ramjet engine [4].

Energy recovery has been used in all kinds of engines in recent years. It is remarkable significant for hypersonic vehicles to build a system with energy recovery for fuel feeding, environment control and radar. What's more, as the flight vehicles powered by scramjet engine could encounter extremely high temperature and heat flux within the combustor [5], and the heat of cooling scramjet would make energy recovery more necessary. The scramjet cooling heat can be used in several ways for energy recovery. The method of Re-cooling cycle for cooling scramjet and power generation is proposed, which converts the thermal energy to mechanical work by a turbine [6-7]. Bao et al. [8-9] enlarged the Re-cooling cycle to hydrocarbon and pointed out power output, which driven a turbo-pump connected to a motor by fuel vapor. Zhang et al. [10] evaluated the performance of a power generation system in which the working fluid was fuel and the generator was driven by the fuel vapor turbine. However, the power output and electrical efficiency of Re-cooling cycle system is relatively low. Based on the principle of work conversion of heat, Closed Brayton Cycle is also proposed for cooling scramjet and power generation. Part of the heat from cooling scramjet can be transferred to available work output [11]. Qin et al. [12] studied an irreversible $\mathrm{CBC}$ thermal management system parameters for cooling scramjet. However, the property of CBC for power 
generation system on scramjet is relative scarce.

A method of exergy is used for analyzing the heat exergy, the exergy destruction and the exergy losses of the system [13-14]. Energy and exergy analysis is useful for thermodynamic cycle. Önder [15] used exergy analysis for an organic Rankine for power generation from waste heat recovery. Shu et al. [16] have analyzed the performance of combined TEG-ORC for heat recovery of ICE (internal combustion engine) and used exergy method for evaluating the feasibility of the system. However, the maximum available work from the heat of cooling scramjet is relative scarce in the special heat sources condition.

In this paper, the maximum available work between the high temperature of scramjet wall and the lower temperature of fuel coolant is discussed. The heat exergy from the cooling scramjet is analyzed. And then the exergy equation is proposed by considering the exergy losses between heat sources and the ideal system according to an ideal system assumption. Thus, the heat of cooling scramjet for power generation is evaluated and the available work between high temperature scramjet wall and low temperature fuel can be recovered. It is meaningful for giving a new method of improving the scramjet cooling performance and having a guidance of power output supply for hypersonic vehicle.

\section{The Net Exergy Transfer by Heat}

For the process of scramjet burning, the equation of energy balance can be expressed as

$$
m_{\text {fuel }} h_{\text {fuel }}+m_{\text {air }} h_{\text {air }}=P_{\text {brake }}+Q_{\text {coolant }}+Q_{\text {else }}+m_{\text {exh }} h_{\text {exh }}
$$

Where $Q_{\text {coolant }}$ is the heat load of cooling scramjet. It consists of the heat of flowing air, the energy of compressing process and the heat from scramjet combustion. It can be written as

$$
Q_{\text {coolant }}=Q_{\text {in }}+Q_{\text {comp }}+Q_{\text {comb }}
$$

Supposed the scramjet wall temperature under the allowable temperature, the scramjet wall heat flux distribution can be gotten. The temperature and heat flux distribution of scramjet wall can be regarded as hot source. According to the heat flux performance of scramjet wall, the heat flow of scramjet wall is expressed as

$$
q=q_{c}+q_{r}=h_{g}\left(T_{g, w, a d}-T_{w}\right)+\sigma \varepsilon_{w, f}\left(\varepsilon_{g} T_{g, s}^{4}-\varepsilon_{w} T_{w}^{4}\right)
$$

Where $q_{c}$ and $q_{r}$ the convective heat flux and the radiative heat flux respectively, $h_{g}$ is the convective heat transfer coefficient, $\varepsilon_{w, f}, \varepsilon_{g}$ and $\varepsilon_{w}$ are the effective emissivity, the gas emissivity and the scramjet wall emissivity, respectively, $\sigma$ is the black body radiation constant, which is $5.67 \times 10^{-8} \mathrm{~W} /\left(\mathrm{m}^{2} \cdot \mathrm{K}^{4}\right)$.

For cooling the scramjet, heat absorbing of fuel coolant can be expressed as

$$
Q_{c}=m_{f} \bar{c}_{p}\left(T_{\text {limit }}-T_{c}\right)
$$

The fuel onboard is as the exclusive coolant for scramjet and cooling capability of the fuel coolant is limited, so the low-temperature heat source for scramjet is finite. It is based on

The original fuel coolant temperature and the highest cooling temperature.

The specific heat of fuel.

The flow rate of fuel. The best way is that the flow rate of fuel for cooling is equal to for combustion.

It is supposed that the temperature distribution of hot and cold sources is show in Figure1. The mechanics of scramjet is as axial symmetry. The scramjet isolator inlet is regarded as $\mathrm{O}$ of coordinate and the flowing direction is along $\mathrm{x}$-axis. The cross-section perimeter of scramjet is taken as $l(x)$. The heat source temperature distribution is $T_{h}(x)$, heat fluxes distribution is $q\left[\mathrm{~T}_{h}(x)\right]$ and cold source temperature distribution is $T_{c}(\mathrm{x})$.

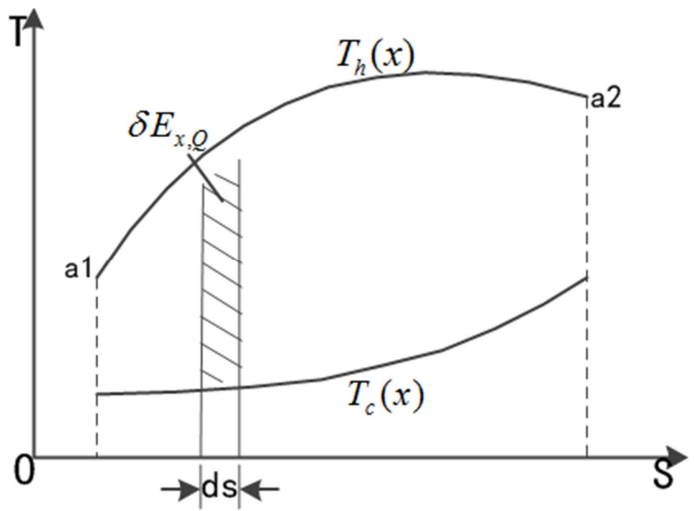

Figure 1. The schematic diagram for calculating exergy.

The theoretical Carnot cycle is supposed between hot and cold sources. In the infinitesimal element with a length $\mathrm{dx}$ of the scramjet wall, the heat flow from scramjet wall can be written as

$$
\delta Q=q\left[\mathrm{~T}_{h}(x)\right] \cdot l(x) d x
$$

According to Fourier's heat conduction law, the heat flux is expressed as

$$
q=-k \frac{\partial T(n)}{\partial n}
$$

In the infinitesimal element with a length $\mathrm{dx}$, the largest heat exergy is written as 


$$
\delta E_{x, Q}=\left(1-\frac{T_{c}}{T_{h}}\right) \delta Q
$$

The heat flow is increasing from the scramjet isolator enter to the scramjet combustion chamber outer. In other words, it can be calculated from location a1 to location a2. The heat exergy input is written as

$$
E_{x, Q}=\int_{a 1}^{a 2}\left[\left(1-\frac{T_{c}(x)}{T_{h}(x)}\right)\left(-k \frac{\partial T(n)}{\partial n}\right) \cdot l(x)\right] d x
$$

\section{Exergy Analysis of Available Work}

There must be a system for power generation by heat conversion between hot and cold source. As shown in Figure2, the exergy equilibrium model is presented in a closed system. According to the relationship of the energy and exergy equilibrium, the energy equation is written as

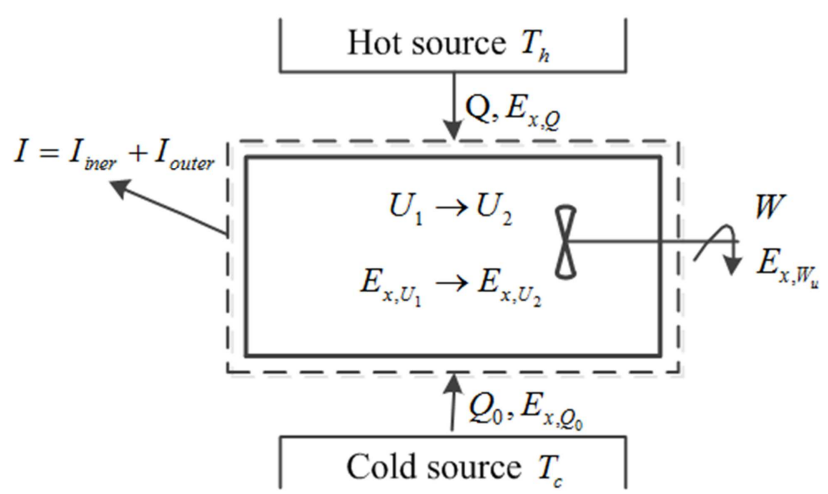

Figure 2. The schematic diagram for the energy and exergy equilibrium model.

$$
Q+Q_{0}=U_{2}-U_{1}+W
$$

The heat exergy input from scramjet wall hot source to the thermal conversion system is calculated by the Eq. (8), the

$$
\begin{gathered}
I_{h}=E_{x, Q}-E_{x, Q, h}=\int_{1}^{2}\left[\left(\frac{T_{c}(x)}{T_{h}(x)-\Delta T_{h}}-\frac{T_{c}(x)}{T_{h}(x)}\right)\left(-k \frac{\partial T(n)}{\partial n}\right) \cdot l(x)\right] d x \\
I_{c}=E_{x, Q}-I_{h}-W_{u}=\int_{1}^{2}\left[\left(\frac{T_{c}(x)+\Delta T_{c}}{T_{h}(x)-\Delta T_{h}}-\frac{T_{c}(x)}{T_{h}(x)-\Delta T_{h}}\right)\left(-k \frac{\partial T(n)}{\partial n}\right) \cdot l(x)\right] d x
\end{gathered}
$$

where $\Delta T_{h}$ and $\Delta T_{c}$ are the heat exchanging temperature differences between the closed system and heat sources.

Therefore, the exergy losses of external irreversible processes are expressed as

$$
\oint \delta I=I_{h}+I_{c}
$$

The available work output in the closed system is written as

$$
\oint \delta W_{u}=W_{u}=\oint \delta E_{x, Q}-\oint \delta I
$$

available work output is obtained from the thermodynamic system, the increment of exergy in the closed system is equal to the difference between original and final exergy of the working fluid and it is supposed that the heat exergy output to fuel cold source is zero. The equation of exergy equilibrium is expressed as

$$
E_{x, Q}=E_{x, U_{2}}-E_{x, U_{1}}+W_{u}+I
$$

where $I$ is the exergy losses in the whole system including $I_{\text {iner }}$ and $I_{\text {outer }}$.

In the infinitesimal element process, the equation of exergy equilibrium is written as

$$
\delta E_{x, Q}=\delta E_{x, U_{2}}-\delta E_{x, U_{1}}+\delta W_{u}+\delta I
$$

The thermodynamic process exergy equilibrium is obtained in the closed system by integral and it can be expressed as

$$
\int \delta W_{u}=\int \delta E_{x, Q}-\int\left(\delta E_{x, U_{2}}-\delta E_{x, U_{1}}\right)-\int \delta I
$$

With thermodynamic processes of a cycle in the closed system, the equation of exergy equilibrium is written as

$$
\oint \delta W_{u}=\oint \delta E_{x, Q}-\oint\left(\delta E_{x, U_{2}}-\delta E_{x, U_{1}}\right)-\oint \delta I
$$

The exergy variety of working fluid in a thermodynamic cycle is zero and the exergy losses in the whole cycle are accumulated. The exergy losses include internal irreversible processes and external irreversible processes. The influence of the internal irreversible processes is ignored and the influence of external irreversible processes is analyzed, which the irreversible processes of the heat exchanging between the closed system and heat sources is discussed. The exergy losses are calculated as

\section{Results and Discussions}

The Mach number of airstream to scramjet isolator inlet is about 1.5 3.5 when the Mach number of airstream is about 6 . The total temperature in the scramjet combustor will be increased due to the heat release and reached about $2500 \mathrm{~K}$. It is supposed that the Mach number of scramjet isolator inlet is 2 and the relationship equations of the total temperature are written as 


$$
\begin{aligned}
\frac{T_{g, t}}{T_{g, \mathrm{~s}}} & =1+\frac{\gamma-1}{2} M a^{2} \\
T_{g, w, a d} & =T_{g, s}+\delta_{a d}\left(T_{g, t}-T_{g, s}\right)
\end{aligned}
$$

where $\gamma$ and $\delta_{a d}$ are 1.4 and 0.9 , respectively.

The heat flow is deceased when the temperature of the scramjet wall increases. According to the Dittus-Boelter equation, the convection heat transfer coefficient of the scramjet internal gas is about $400 \mathrm{~W} / \mathrm{m}^{2} \cdot \mathrm{K}$, all of the assumption emissivity are 0.85 . It is supposed that the temperature differences between the closed system and heat sources are $\Delta T_{h}=100 \mathrm{~K}$ and $\Delta T_{c}=50 \mathrm{~K}$, respectively. As shown in Figure 3, the variation of the heat flow, the heat exergy and the available work with one heat exchanging area from the scramjet wall are presented along the difference scramjet wall temperature. The heat flow, the heat exergy and the available work from the scramjet wall are increased with the temperature of scramjet wall from $1200 \mathrm{~K}$ to $1000 \mathrm{~K}$, which is lower than currently promised biggest temperature for materials [17]. However, the heat flow is changed larger than the heat exergy and the available.

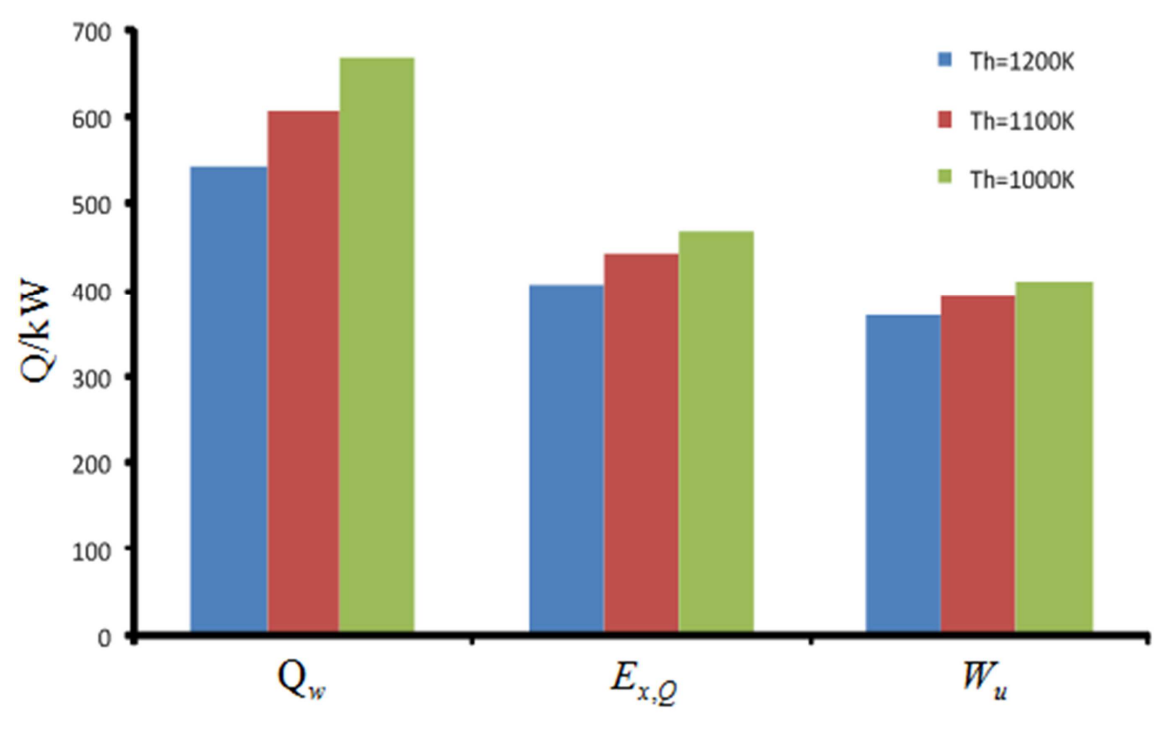

Figure 3. The variation of the heat flow, heat exergy and available work with the difference scramjet wall temperature.

Figure 4 shows the variation of the external exergy losses with the difference scramjet wall temperature. The exergy losses of external irreversible processes are increased with the temperature of scramjet wall from $1200 \mathrm{~K}$ to $1000 \mathrm{~K}$. Therefore, it is helpful for decreasing the exergy losses to increasing the hot source temperature which is limited by the scramjet wall temperature. Likewise, the exergy efficiency of the closed system is defined as the ratio of the available work and the heat flow, the exergy efficiency of the closed system is higher when the scramjet wall temperature is increased as shown in Figure 5. Because the heat of the scramjet wall is decreased and the potential work of the heat is improved with the increasing of the hot source temperature.

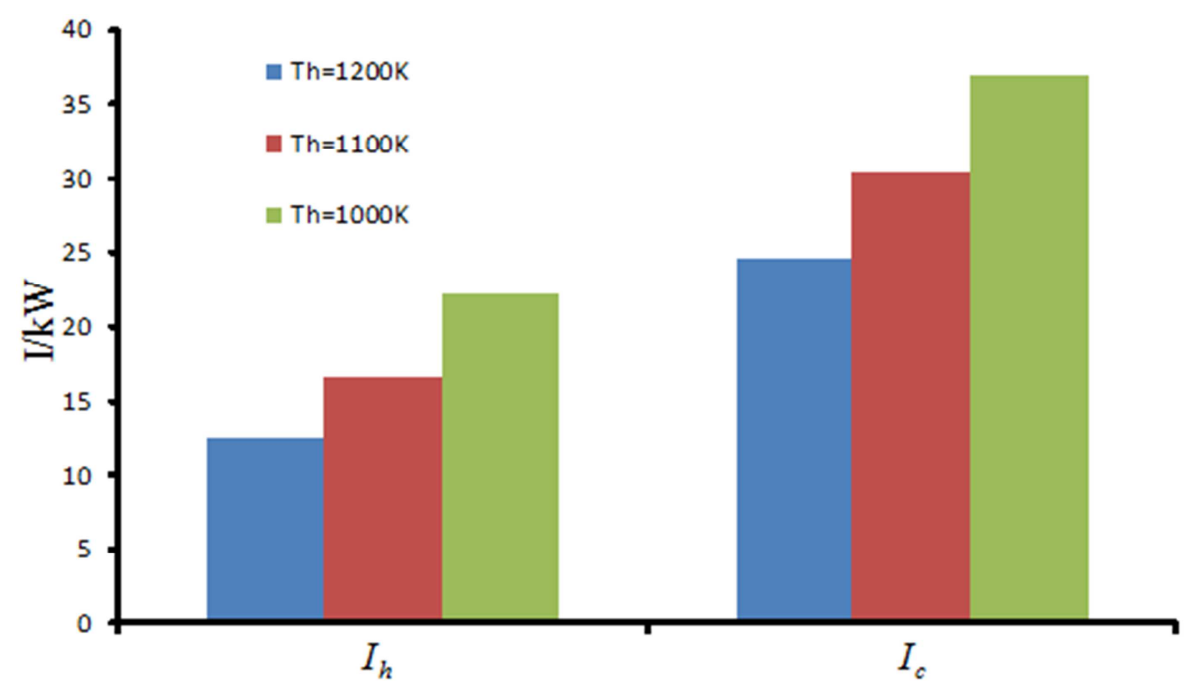

Figure 4. The variation of the external exergy losses with the difference scramjet wall temperature. 


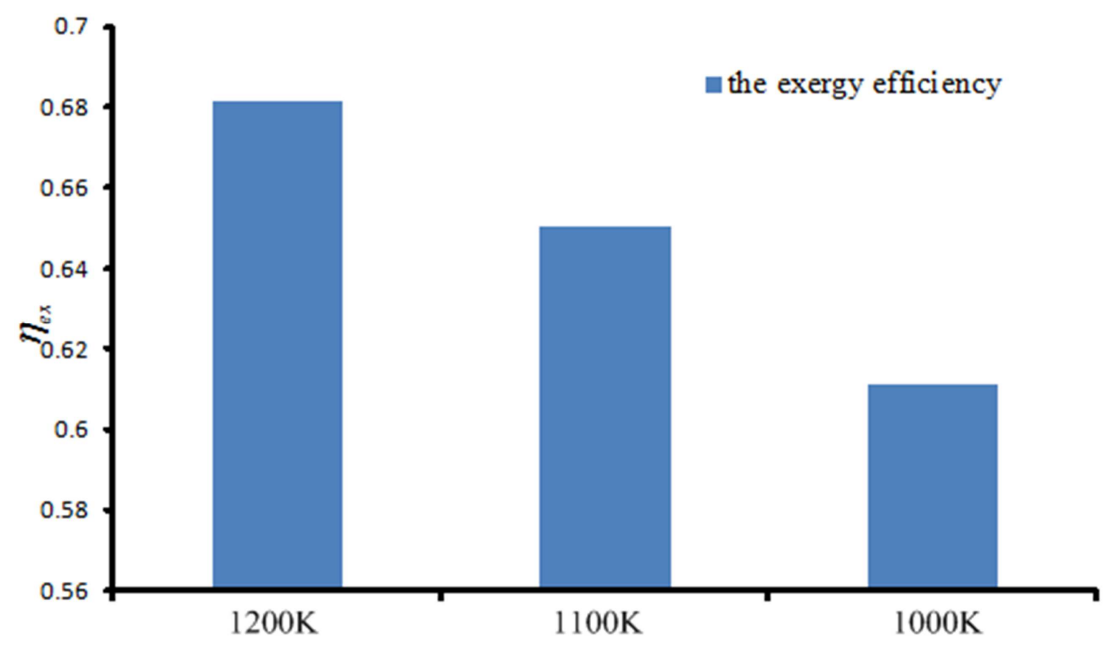

Figure 5. The variation of the exergy efficiency with the difference scramjet wall temperature.

The heat exchanging temperature differences between the closed system and heat sources have a big effect on the external exergy losses. In order to decrease the area of heat exchange between the closed system and heat sources, the heat exchanging temperature differences must be enough large. As shown in Figure 6, the variation of the external exergy losses and the exergy efficiency are presented along the increase of $\Delta T_{h}$. Because of the large scramjet wall heat flux, the heat exchanging temperature difference is adapted to the heat exchanging process. The exergy losses of external irreversible processes are increased, $I_{h}$ is increased from $5.9 \mathrm{~kW}$ to $12.3 \mathrm{~kW}$ by the temperature difference from $50 \mathrm{~K}$ to $100 \mathrm{~K}, I_{c}$ is increased from $23.6 \mathrm{~kW}$ to $24.9 \mathrm{~kW}$, and the exergy efficiency of the closed system is decreased from $69.6 \%$ to $68.2 \%$ as $\Delta T_{c}$ is supposed $50 \mathrm{~K}$.

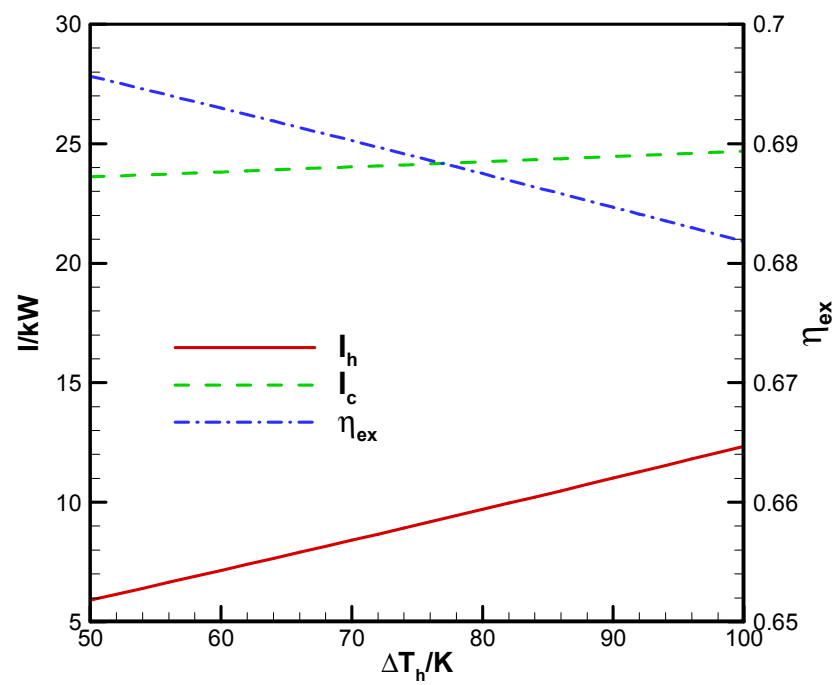

Figure 6. The variation of the external exergy losses and the exergy efficiency with $\Delta T_{h}$.

As shown in Figure 7, the variation of the external exergy losses and the exergy efficiency are presented along the increase of $\Delta T_{c}$. The exergy loss between hot source and the closed system is not changed while it increases between cold source and the closed system. $I_{h}$ is about $12.3 \mathrm{~kW}$ as $\Delta T_{h}$ is supposed $100 \mathrm{~K}, I_{c}$ is increased from $9.7 \mathrm{~kW}$ to $34.0 \mathrm{~kW}$ by the temperature difference from $20 \mathrm{~K}$ to $70 \mathrm{~K}$, and the exergy efficiency of the closed system is decreased. From the Eq. (15) and (16), the heat exchanging temperature difference between cold source and the closed system has no effect on the $I_{h}$. The exergy efficiency of the closed system keeps the region of $66 \% \sim 71 \%$ when $\Delta T_{h}$ changes from $50 \mathrm{~K}$ to $100 \mathrm{~K}$ and $\Delta T_{c}$ changes from $20 \mathrm{~K}$ to $70 \mathrm{~K}$.

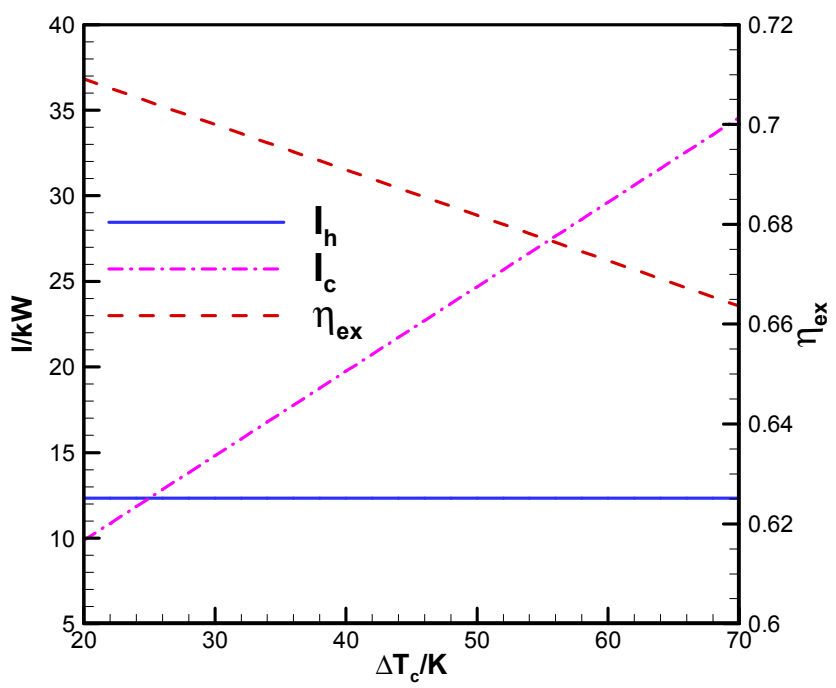

Figure 7. The variation of the external exergy losses and the exergy efficiency with $\Delta T_{c}$.

\section{Conclusion}

In this paper, the heat of cooling scramjet for the available work is evaluated and the model of heat exergy analysis is established. The external exergy losses are analyzed in different heat exchanging temperature differences. There is large available work from the heat of cooling scramjet for power generation and it is reached to $370.3 \mathrm{~kW}$, the exergy efficiency of the closed system is $68.2 \%$ when the scramjet 
wall temperature is $1200 \mathrm{~K}$. The external exergy losses and the exergy efficiency have been largely changed with the heat exchanging temperature differences between the closed system and heat sources. The heat exchanging temperature differences decrease, the external exergy losses decrease and the exergy efficiency increases. However, the heat exchanging temperature differences would be adapted to heat exchanging processes and decreasing the acreage of heat exchange.

Evaluation the available work has a big significance for power generation from the heat of cooling scramjet. The power output of the closed system can be utilized for the hypersonic vehicle. Evaluation the heat of cooling scramjet for the available work would give a new method of improving the scramjet cooling and have a guidance for power generation.

\section{Acknowledgements}

This research work is supported by National Natural Science Foundation of China (General Program, No. 51505487), and the authors thank the reviewers for their valuable advice on this paper.

\section{Nomenclature}

$\mathrm{T}$

q

$\mathrm{k}$

$\mathrm{U}$

Q

$\mathrm{E}$

$\mathrm{c}_{\mathrm{p}}$

$\mathrm{m}$

$\mathrm{h}$

W

I

$\mathrm{Ma}$

$\Delta T$

Greeks symbols

$$
\eta
$$

$$
\varepsilon
$$

$\gamma$

$\sigma$

\section{Subscripts}

$\mathrm{w}$

$\mathrm{h}$

$\mathrm{c}$

$\mathrm{x}, \mathrm{Q}$

$\mathrm{x}, \mathrm{U}$

1,2

ex

$\mathrm{f}$

g, s

$\mathrm{g}, \mathrm{t}$

g, w, ad cross-section perimeter of scramjet (m) temperature $(\mathrm{K})$

heat flux $\left(\mathrm{W} / \mathrm{m}^{2}\right)$

thermal conductivity $(\mathrm{W} /(\mathrm{m} \mathrm{K}))$

thermodynamic energy rate (W)

heat flow rate $(\mathrm{W})$

exergy rate $(\mathrm{W})$

specific heat $(\mathrm{J} /(\mathrm{kg} \mathrm{K}))$

mass flow rate $\mathrm{kg} / \mathrm{s}$ )

enthalpy $(\mathrm{J} / \mathrm{kg})$

available work (W)

exergy loss (W)

mach number

temperature difference $(\mathrm{K})$

efficiency (\%)

emissivity

the ratio of specific heat

the black body radiation constant

scramjet internal wall

hot source

cold source

$\mathrm{x}$-axis and heat flow rate

thermodynamic energy

state points of the system

exergy

fuel

static temperature

total temperature

recovery temperature

\section{References}

[1] Chang J, Bao W, Yu D. Hypersonic inlet control with pulse periodic energy addition. Proceedings of the Institution of Mechanical Engineers, Part G: Journal of Aerospace Engineering 2009; 223: 85-94.

[2] Mahapatra D, Jagadeesh G. Shock tunnel studies on cowl/ramp shock interactions in a generic scramjet inlet. Proceedings of the Institution of Mechanical Engineers, Part G: Journal of Aerospace Engineering 2008; 222: 1183-91.

[3] Kontis K. Flow control effectiveness of jets, strakes, and flares at hypersonic speeds. Proceedings of the Institution of Mechanical Engineers, Part G: Journal of Aerospace Engineering 2008; 222: 585-603.

[4] Bao W, Qin J, Yu D. Integrated thermal management method of energy based on Closed Brayton Cycle for scramjet. 42nd AIAA/ASME/SAE/ASEE Joint Propulsion Conference. AIAA 2006-4685.

[5] Yang Q, Chang J, Bao W. Thermodynamic analysis on specific thrust of the hydrocarbon fueled scramjet. Energy 2014; 76: 552-8.

[6] Qin J, Bao W, Zhou W, Yu D. Performance cycle analysis of an open cooling cycle for scramjet. Proceedings of the Institution of Mechanical Engineers, Part G: Journal of Aerospace Engineering 2009; 223: 599-607.

[7] Bao W, Qin J, Zhou W, Yu D. Parametric performance analysis of multiple re-cooled cycle for hydrogen fueled scramjet. International Journal of Hydrogen Energy 2009; 34: 7334-41.

[8] Bao W, Qin J, Zhou W, Zhang D, Yu D. Power generation and heat sink improvement characteristics of recooling cycle for thermal cracked hydrocarbon fueled scramjet. Sci China Technol Sci 2011; 54: 955-63.

[9] Bao W, Zhang D, Qin J, Zhou W. Performance analysis on fuel turbo-pump and motor system of scramjet engine. 10th International Energy Conversion Engineering Conference. AIAA 2012-4159.

[10] Zhang D, Qin J, Feng Y, Ren F, Bao W. Performance evaluation of power generation system with fuel vapor turbine onboard hydrocarbon fueled scramjets. Energy 2014; 77: 732-741.

[11] Qin J, Bao W, Zhou W, Yu D. Thermal management system performance analysis of hypersonic vehicle based on Closed Brayton Cycle. 44th AIAA/ASME/SAE/ASEE Joint Propulsion Conference \& Exhibit. AIAA 2008-5178.

[12] Qin J, Zhou W, Bao W, Yu D. Thermodynamic analysis and parametric study of a closed Brayton cycle thermal management system for scramjet. International Journal of Hydrogen Energy 2010; 35: 356 - 364.

[13] Christopher K, Thomas S, Nikolaos M. Exergy analysis of renewable energy sources. Renewable Energy 2003; 28: 295310 .

[14] Park S, Pandey A, Tyagi V, Tyagi S. Energy and exergy analysis of typical renewable energy systems. Renewable and Sustainable Energy Reviews 2014; 30: 105-123.

[15] Önder K. Energy and exergy analysis of an organic Rankine for power generation from waste heat recovery in steel industry. Energy Conversion and Management 2014; 77: 108-117. 
[16] Shu G, Zhao J, Tian H, Liang X, Wei H. Parametric and exergetic analysis of waste heat recovery system based on thermoelectric generator and organic rankine cycle utilizing R123. Energy 2012; 45: 806-816.
[17] Aiichiro T, Hiroyuki Y, Kazuyuki M. Advanced thermal protection systems for reusable launch vehicles. 10th International Space Planes and Hypersonic Systems and Technologies Conference, 2001, Japan, 2001-1909. 